\title{
A IMPORTÂNCIA DO TRABALHO DO TRADUTOR DERRIDA PARA O TRABALHO DO FILÓSOFO DERRIDA
}

\author{
Erica Luciene Lima de Paulo \\ Pontifícia Universidade Católica de Campinas \\ erica.limadepaulo@gmail.com
}

"Dis-moi ce que tu penses de la traduction, je te dirais qui tu es"

(Heidegger, apud Derrida 1987, p. 17)

Resumo: Pretende-se mostrar que a experiência de Jacques Derrida ao traduzir L'Origine de la géométrie, de Edmund Husserl, ao lado de sua preocupação com a tradução de seus próprios textos para outras línguas e dos textos cujas traduções "consagradas" ele utiliza, acabam por determinar e colocar em cena algumas de suas noções filosóficas. Assim, pretende-se mostrar que a maneira como o filósofo lê os textos traduzidos e seus comentários sobre as traduções não são marginais (externos), mas sim elementos primordiais para a lógica textual da desconstrução e manifestam, entre outras noções, o enxerto, o suplemento e o double bind. Palavras-chave: tradução, desconstrução, Jacques Derrida.

\section{THE IMPORTANCE OF DERRIDA'S WORK AS A TRANSLATOR FOR DERRIDA AS A PHILOSOPHER}

\begin{abstract}
This essay aims at showing that Jacques Derrida's experience translating Edmund Husserl's L'Origine de la géométrie, combined with his interest in both the translation of his own texts into other languages and the texts whose "accepted" translations he uses, ultimately define and bring to the forefront some of this philosophical concepts. This essay also seeks to show that Derrida's reading of translated texts and his comments on translations are not marginal, but rather key elements underlying the
\end{abstract}


logic of deconstruction writings and display concepts such as graft, supplement and double bind, among others.

Keywords: translation, deconstruction, Jacques Derrida.

Mais de quarenta anos de trabalho, uma influência inegável em várias áreas do conhecimento (filosofia, psicanálise, teoria literária, tradução, arquitetura, política, história, cinema, artes, para citar algumas), cerca de oitenta livros publicados, inúmeros artigos e congressos, enfim, uma obra gigantesca que justifica a afirmação do presidente francês Jacques Chirac na ocasião do falecimento de Jacques Derrida: "Com ele, a França deu ao mundo um dos mais importantes intelectuais do nosso tempo" (apud Mendes, 2004, nossa tradução). Sete anos após sua morte, publicações sobre sua obra ou estudos relacionados à desconstrução continuam a mostrar a importância do pensamento derridiano, apesar das também inúmeras críticas a ele dirigidas pelo menos nas últimas três décadas. É certo que a leitura de qualquer texto de Derrida não deixa o leitor indiferente. É sempre um caso de amor ou ódio, que seria questionado por ele como várias outras dicotomias do pensamento ocidental. No Brasil, o pensamento da desconstrução recebeu adeptos especialmente nos departamentos de literatura e tradução, o que se justifica pela enorme produção de Derrida nas duas áreas, envolvendo questões de linguagem, produção de sentidos, identidade, valores éticos e estéticos. Seu envolvimento com a tradução, nosso interesse aqui, começou antes mesmo de suas publicações na área da filosofia. Sua primeira publicação, em 1962, foi uma longa introdução à sua tradução do livro L'Origine de la géométrie, de Edmund Husserl. Nesse ensaio, além de vários temas que seriam desenvolvidos depois em sua obra, Derrida trata de questões da tradução propriamente dita.

O termo pelo qual seu pensamento ficou conhecido, "déconstruction", é o resultado de uma leitura da Destruktion de Heidegger. Em seu livro sobre o filósofo alemão, Derrida usa o termo em francês seguido de Destruktion entre parênteses (cf. Derrida, 
1987, p. 35 e 41), ou seja, desde o início, a desconstrução é o resultado de um ato tradutório. A partir do momento que seu pensamento passa a ser conhecido como "desconstrução" começam, também, os questionamentos sobre uma definição do termo ${ }^{1}$. Em um dos momentos em que tenta uma definição, Derrida diz que seria melhor usar o termo no plural e justifica: "La déconstruction au singulier ne peut pas être simplement 'appropriée' par qui que ce soit ou par quoi que ce soit. Les déconstructions sont les mouvements de ce que j'ai appelé l' 'ex-appropriation'” (1990c, p. 261) “A desconstrução no singular não pode ser simplesmente 'apropriada' por quem quer que seja ou por o que quer que seja. As desconstruções são os movimentos daquilo que chamei de “ex-apropriação'” (Derrida, 1991, p. 194)². Posteriormente, Derrida faz uma afirmação que mostra mais uma vez a importância da língua em toda sua obra: “si j'avais à risquer une seule définition de la déconstruction, je dirais simplement: plus d'une langue" (Derrida, 1998, p. 253) ("se fosse arriscar uma única definição da desconstrução, eu diria simplesmente: mais de uma língua"). Estas duas afirmações nos permitem observar a relação direta com o ato da tradução, especialmente quando mostra a existência de mais de uma língua no texto, a complexidade da constituição do sentido e o papel do autor (tradutor) como alguém que determina o querer-dizer textual.

Depois da experiência como tradutor, o filósofo parece não mais se esquecer de que o Husserl em francês é o seu Husserl, o Husserl de Derrida, assim como todos os textos traduzidos aos quais ele recorre serão textos contaminados por uma leitura e escrita tradutórias. A conscientização da responsabilidade e da influência do tradutor ao produzir um novo texto é explícita, sobretudo nas ocasiões em que Derrida recorre às traduções publicadas, estratégia adotada desde essa tradução de Husserl, como pode ser confirmado com a nota que diz: "Pour la traduction des concepts usuels de la langue husserlienne, nous nous sommes naturellement conformé aux usages consacrés par la traduction des grands ou- 
vrages de Husserl" (1962, p. 12) ("Para a tradução de conceitos usuais da língua husserliana, naturalmente nos conformamos com os usos consagrados pela tradução das grandes obras de Husserl"), traduzidas por Ricoeur, Bachelard e Élie.

Ao mesmo tempo em que Derrida parece contra-assinar a tradução, chama o outro à responsabilidade, provocando um novo jogo, possibilitando a conexão entre duas leituras, a de Derrida que lê o texto traduzido e a do texto traduzido que lê o texto original.

Derrida acaba procurando no texto traduzido a mesma precisão e o mesmo cuidado com a singularidade do texto apresentadas por ele em seu próprio texto, ao contrário do que dizem muitos dos seus detratores. Está em jogo a responsabilidade de assumir uma leitura e escritura levando em conta a alteridade, considerando, ao mesmo tempo, a mise en abyme característica de todo texto, o fato de não ser possível sair de sua interioridade e o fato sempre existir a restância. Isso equivale a afirmar que não existe o fora do texto, pois todo texto é um texto sobre um texto sobre um outro texto, e que não há contexto totalmente determinável, já que não se pode saturar um contexto.

Podemos levantar algumas contribuições de Derrida à tradução que corroboram as várias afirmações sobre o cuidado derridiano com a(s) língua(s) e com a letra do texto. A propósito do papel de Derrida como tradutor, encontramos em Siscar uma retomada de grande relevância:

Claro, como tradutor, Derrida contribuiu para a língua filosófica francesa propondo interferências criativas; como tradutor de Husserl, criou o vouloir-dire (querer-dizer), por exemplo, em lugar de Bedeutung (significação); como tradutor ocasional da linguagem heideggeriana associou o es gibt (il y a; há, existe) ao donner (dar); trouxe o acontecer para a rede de sentidos do événement (evento, acontecimento), como modo do vir (venir, avènement, avenir, aventure); reinterpretando proposições de Kant, criou uma cadeia de referências extremamente profícua com o tom; 
os exemplos são muitos de como se traduz assumindo a responsabilidade, inclusive teórica, de sua tradução. (Siscar, 2000, p. 66)

Dedicando-se especialmente a explicar uma opção de tradução, o próprio Derrida desenvolve o texto Qu'est-ce qu'une traduction 'relevante'? (O que é uma tradução 'relevante’?), no qual justifica sua tradução de seasons por relève e não por tempère, utilizando algumas passagens da tradução de um texto literário, Le Marchand de Venise ( $O$ mercador de Veneza), de Shakeaspeare, para o francês (feita por François-Victor Hugo). Esse texto é uma comprovação da preocupação de Derrida com o idiomático do texto, cujo efeito é duplicado ao se tratar de um texto traduzido.

De acordo com Derrida, "when mercy seasons justice" não seria traduzido por "quand le pardon tempère la justice", como faz Hugo, mas por "quand le pardon relève la justice (ou le droit)"(1999, p. 42) ("quando o perdão releva a justiça (ou o direito)”) (2000, p. 37). A respeito da tradução, o filósofo afirma:

Mais à cette traduction de François-Victor Hugo ("tempère") qui n'est pas mauvaise, je serais tenté d'en substituer une autre. Ce ne sera pas une vraie traduction, surtout pas une traduction relevante. Elle ne répondra pas au nom de "traduction". Elle ne rendra pas, elle ne s'acquittera pas, elle ne restituera pas tout, elle ne paiera pas toute sa dette, et d'abord à un concept supposé, à une identité de sens alléguée du mot "traduction". Elle ne va pas relever de ce qu'on appelle couramment une traduction, une traduction relevante. $(1999, \text { p. } 42)^{3}$

Completa que a tradução de seasons por relève faz parte de sua história, de uma iniciativa de traduzir o Aufheben, Aufhebung de Hegel, realizada há mais de trinta anos, que acabou por ser a 
tradução consagrada em francês. Derrida justifica sua tradução de três maneiras: considerando a conotação culinária relever, encontrada também em to season (relevar como condimentar, temperar); considerando a ideia de exaltação da justiça (relevar como sublimar, exaltar); considerando a ideia dupla de substituir e elevar, que determinou a sua escolha por relève ao traduzir o termo hegeliano (cf. 1999, p. 42-4; 2000, p. 37-9). Para Derrida, essas três justificativas resumem as razões de sua escolha da melhor tradução possível, a mais econômica, que "permitia traduzir tantas palavras, até mesmo tantas línguas, denotações e conotações em uma única palavra" (2000, p. 41).

Relevante não é unicamente francês, pois também faz parte da língua inglesa (e da portuguesa, embora em cada uma possa ter diferentes nuanças). O enfoque derridiano em Qu'est-ce qu'une traduction 'relevante'? diz respeito à lei da economia, à possibilidade de traduzir uma palavra por outra levando em conta o maior número de jogos de sentido possível.

Une traduction relevante serait donc, tout simplement, une 'bonne' traduction, une traduction qui fait ce qu'on attend d'elle, en somme, une version qui s'acquitte de sa mission, honore sa dette et fait son travail ou son devoir en inscrivant dans la langue d'arrivée l'équivalent le plus relevant d'un original, le langage le plus juste, approprié, pertinent, adéquat, opportun, aigu, univoque, idiomatique, etc. (Derrida, 1999 , p. 24$)^{4}$

Gostaríamos de destacar um dos sentidos do relever: a substituição. Uma tradução relevante é também aquela que substitui o outro. Essa substituição acontece dentro de um jogo de rastros e suplementos constitutivos de um texto e sempre poderá gerar novas substituições, desencadeando novas interpretações e provocando novos efeitos, nos remetendo à ideia derridiana de transformação 
de um texto em outro (cf. Derrida, 1975). Por um lado, é necessário considerar a lei do texto de partida e respeitá-la; por outro, é necessário transformar o texto do outro para que possa ser a promessa de um acontecimento textual na língua da tradução.

Malgré tout, me semble-t-il, la traduction doit s'efforcer d'être le plus fidèle possible, non par souci d'exactitude calculable, mais parce qu'elle nous rappelle à la loi de l'autre texte, à son injonction, à sa signature, à cet autre événement en tant qu'il a déjà eu lieu avant nous, et dont nous devons répondre en héritiers. Il est là, et à traduire, avant nous, devant nous: hétéronomie qui fait que j'accepte la loi de l'autre, non pas en y obéissant passivement, mais en contresignant, en inventant une signature qui, dans ma langue, dans une situation tout à fait différente, dans une langue incommensurable, s'allie très étrangement à l'autre et souscrit à la loi de l'autre. (Derrida, 1998, p. 262-3) ${ }^{5}$

A fidelidade em questão diz respeito à dívida instaurada pela singularidade do texto e pela sua assinatura (estilo e tom), que reivindicam uma certa atenção à letra do texto e a consideração do texto traduzido como um novo texto, no qual os jogos de sentido serão outros.

Ao dizer que a singularidade do texto deve ser respeitada, que se deve levar em conta questões de língua e de assinatura, enfim, que para ler um texto é preciso considerar a lógica do próprio texto, Derrida mostra-nos que a tradução é um assunto sério.

\section{Derrida e seus tradutores}

Ao lado de sua própria experiência como tradutor, é preciso considerar que Derrida é o filósofo mais traduzido no mundo, aspectos que o levam constantemente a pensar a tradução. O re- 
sultado dessa conscientização aparece em seus textos e possibilita afirmações como a de uma de suas tradutoras americanas, Barbara Johnson, para quem "o trabalho de Derrida sempre foi, na verdade, (sobre) tradução" (1998, p. 28) e para quem "todo o empreendimento filosófico de Derrida pode ser visto como uma análise do processo de tradução que atua em qualquer texto" (1998, p. 31).

Derrida não só questiona as opções de tradução, mas também a omissão da tradução. Nesse sentido, um caso emblemático é sua discussão da supressão do penúltimo parágrafo de Discours de la méthode, no qual Descartes afirma: “et si j'écris en français, qui est la langue de mon pays ..." (cf. Derrida, 1990b, p. 283) ("e se escrevo em francês, que é a língua do meu país...”). Derrida vê nesse enunciado um desafio ignorado pelas traduções para o latim de Étienne de Courcelles e da edição Adam et Tanney. No primeiro caso, a passagem simplesmente desaparece e, no segundo, a omissão é assinalada por meio da afirmação "il n'y avait pas lieu de (le) traduire en effet" (cf. Derrida, 1990b, p. 308) ("realmente não tinha motivos para traduzir"). Ao interpretar essa afirmação, Derrida entrelaça três diferentes códigos: o jurídico, que rege a obrigação ("não é preciso", "é proibido" traduzir); o da utilidade técnica (não é útil traduzir) e o da conveniência social (é inconveniente traduzir) (cf. Derrida, 1990b, p. 313). Se as traduções deixassem claro, em latim, que Descartes escreve em francês, explicitariam ao leitor do latim que está lendo uma tradução, ou seja, que o texto filosófico em questão, geralmente escrito em latim, aparece inicialmente na língua do outro.

Derrida lembra que a questão principal é: "quel sens y aurait-il à dire en latin "je parle français'?" ("que sentido teria dizer em latim “eu falo francês'?”) Completa ainda:

Ainsi quand un "original" parle de sa langue en parlant sa langue il prépare une sorte de suicide à la traduction, comme on dit suicide au gaz ou suicide par le feu. Plutôt suicide par le feu, car il laisse détruire presque sans reste, 
sans reste apparent dans le dedans du corpus. (Derrida, 1990b, p. 309) ${ }^{6}$

A frase em questão é intraduzível não devido a uma dificuldade linguística, mas à sua performatividade. O performativo, segundo Austin, diz respeito ao "quando dizer é fazer", isto é, a afirmação de que escreve em francês já é a concretização do ato da escrita. Sua resistência à tradução diz respeito à mudança de língua: "changer de langue c'est, dans ce cas, annuler le coeur même du 'signifié "' (mudar de língua é, nesse caso, abater o próprio coração do 'significado') (Derrida, 1990b, p. 312).

Os enunciados performativos não são os únicos a provocarem a discussão sobre a intraduzibilidade. O "coeur" francês também dará a Derrida a oportunidade de colocar em cena a tradução do idiomático. Com o uso de "par coeur", Derrida (1992a) mostra a (im)possibilidade da tradução da expressão idiomática relacionada à própria (im)possibilidade de "definir" poesia. O "par coeur" não trata apenas do sentimento, do coração, mas da memória, da cabeça. Como ocorre nas poesias, a definição de Derrida possibilita a disseminação de sentidos, não só no interior da língua francesa, como também nas outras línguas. A dificuldade de traduzir poesia excede o espaço poético e alcança a sua definição, ou seja, o texto Che cos'è la poesia? mostra que a experiência da tradução é tão (im)possível quanto a do poema. A tradução, como a poesia, pode ser comparada ao ouriço: vulnerável e perigoso, não se consegue tocar, mas está lá. Afasta e aproxima ao mesmo tempo.

A traduzibilidade é colocada em xeque em situações em que o idiomático é mais manifesto, tanto no caso do francês como no caso da outra língua inserida no texto derridiano. Em Limited Inc., por exemplo, Derrida afirma: "J'aurais pu simuler ce qu'on appelle en français un 'faux départ' (j'insiste auprès du traducteur pour qu'il garde les guillemets, les parenthèses, les italiques, et le français) $" . .(1990 \mathrm{c}, \text { p. 63 })^{7}$ 
O enxerto do comentário entre parênteses explicita a conscientização de Derrida de que o texto passará por pelo menos uma tradução, já que, por se tratar de sua discussão com o americano Searle a respeito da teoria anglo-americana dos atos de fala, estava destinado a ser publicado primeiramente em inglês. A advertência parentética não diz respeito somente ao francês, mas também aos recursos gráficos utilizados na palavra, essenciais para a interpretação dos jogos derridianos. Ainda em Limited Inc., mais adiante, fala novamente sobre a tradução, desta vez dando nome ao tradutor:

Je ne sais pas comment Sam Weber traduira 'contre-pied'. Je précise, à son intention que je l'entends d'abord, depuis mon adolescence, dans le code du football: ruse active pour surprendre l'adversaire engagé dans l'autre direction. $(1990 \text { c, p. 138-9) })^{8}$

A insistência inicial e a quase imposição no sentido de preservar a forma como o francês é utilizado dão lugar a um tratamento mais pessoal: o tradutor é chamado pelo nome e incluído no texto, sugerindo uma aproximação e um maior acolhimento ao trabalho de Weber. Os dois exemplos podem despertar o interesse do leitor para a tradução, convidando-o a conferir quais foram as saídas encontradas na língua inglesa.

O reconhecimento da dificuldade que cerca a tradução é expresso por meio de "recados" para o tradutor no decorrer de vários textos derridianos. Survivre é exemplar porque não apresenta apenas notas ao tradutor, mas também notas do tradutor (Derrida) a respeito do ato tradutório no mesmo momento em que ele está ocorrendo. Em Passions, Derrida afirma em nota: “On devrait ne pas devoir [difficile à traduire en anglais, mais je l'ai fait exprès: laisser le français dans le texte]" (1993, p. 75) ("On devrait ne pas devoir (difícil de traduzir para o inglês, mas fiz por gosto: deixar o francês no texto)”) (1995, p. 53). Por um lado, ele impõe seu 
"gosto", seu desejo de não traduzir; por outro, deixa claro que está criando uma dificuldade adicional para o tradutor, quase uma imposição para que o francês seja mantido no texto em inglês. $\mathrm{O}$ próprio Derrida, ainda nas notas de Passions, fala sobre a imposição da língua ao abordar a tradução da palavra intraitable:

Si ailleurs il s'est souvent imposé, le mot français intraitable est sans doute difficile à traduire ... Autant dire que le mot intraitable est lui-même intraitable (par exemple intraduisible) - et c'est pourquoi j'ai dit qu'il était imposé. (1995, p. $84-5)^{10}$

Novamente Derrida está tratando a intraduzibilidade da palavra francesa para o inglês, o que poderia provocar um questionamento de um tradutor que não enfrenta o mesmo problema ao traduzir para uma terceira língua.

Apesar de terem sido escritos em francês, Limited Inc. e Passions destinavam-se a ser publicados inicialmente em inglês; o que justifica a atenção de Derrida à (im)possibilidade de traduzir para esta língua. Ao pensarmos na tradução do francês para outras línguas, as dificuldades serão outras e, a elas, será acrescida a questão da (ir)relevância de falar sobre o desafio de traduzir para uma língua que não é a língua do texto traduzido, uma vez que, em princípio, importa ao leitor de uma língua a dificuldade de traduzir para a sua própria língua, não para uma terceira.

Talvez o exemplo em que o idiomático derridiano se manifesta mais irredutivelmente seja o título, considerado o nome próprio do texto. Como para dramatizar a intraduzibilidade do nome próprio, Derrida denomina seus textos de maneira a dificultar e por vezes impedir a tradução, na medida em que o "impedimento" está ligado à necessidade da tradução, à ideia do double bind (a necessidade e a impossibilidade de traduzir).

O cuidado com o idiomático da língua francesa é repetido em relação à língua do outro. Derrida mostra que está atento às inevi- 
táveis transformações do texto traduzido (com as quais nem sempre concorda) mediante seus comentários e modificações às traduções explicitadas por meio de notas ou no corpo do texto. Se, por um lado, Derrida mostra-se hospitaleiro às traduções consagradas, acolhendo-as em seu texto, por outro, em vários momentos deixa claro que tem restrições em aceitá-las. Em La pharmacie de Platon, ele afirma:

On aura remarqué que nous utilisons une traduction consacrée de Platon, celle des éditions Guillaume Budé, qui fait autorité. Ici, pour le Phèdre, celle de Léon Robin. Nous continuerons à le faire, en insérant toutefois, quand cela nous paraîtra opportun et, quant à notre propos, pertinent, le texte grec entre parenthèses. $\left(1992 b\right.$, p. 266) ${ }^{11}$

Ao afirmar que pode lançar mão do uso parentético, Derrida não assinala simplesmente que se trata de uma tradução. A inclusão da outra língua permite um jogo de interpretação inexistente sem essa presença. Ao que parece, a questão é chamar a atenção do leitor por meio de um ótimo estratagema: deixar claro que a tradução é "corrente" na língua, mas que pode modificá-la ou acrescentar o termo na língua original, por meio do procedimento do enxerto, se o "contexto o exigir". Dessa forma, aponta o problema e simultaneamente mostra que a solução é não ter solução, pois, a partir do valor de uso que a palavra assume na tradução, qualquer alternativa surge como suplemento, mas não apaga a opção anterior.

$\mathrm{O}$ caso do pharmakon ilustra muito bem a irredutibilidade da tradução e suas consequências para uma determinada interpretação filosófica: ao se priorizar um ou outro polo de significação, remédio ou veneno, estará se privilegiando também uma determinada noção de escritura. O pharmakon faz parte dos termos utilizados por Derrida que possuem um valor duplo, indecidível, e que não devem ser reduzidos a um só polo de significação. Além de phar- 
makon, outros muito citados são a différance e o double bind, em que, já na língua de partida (respectivamente, o grego, o francês e o inglês), aparece a impossibilidade de eliminar a aporia que determina a articulação textual. Embora muitas vezes sejam apontados como intraduzíveis, esses termos continuam sendo traduzidos, como pode ser comprovado em relação ao double bind, com as opções apresentadas por, entre outros, Nascimento (duplo elo, dupla ligação, dupla obrigação, dois gumes, duplo bando, dupla ereção, dupla banda, dupla borda ou beira, 2001, p. 99) e Viscardi (duplo vínculo, cf. Chamberlain, 1998, p. 51).

O caso do termo alemão Geist, abordado em De l'esprit é semelhante ao do pharmakon. No início do livro, Derrida afirma que De l'esprit é um título muito francês para "fazer ouvir" o Geist. Completa ainda:

Peut-être en tout cas serons-nous plus justement sensibles à sa germanité si nous le laissons résonner depuis une langue étrangère pour le mettre à l'épreuve de la traduction, ou plutôt si nous mettons à l'épreuve sa résistance à la traduction. Et si nous mettons notre langue à la même épreuve. $(1987, \text { p. } 16-7)^{12}$

O jogo constante com a língua alemã no texto em francês leva a uma contaminação entre as línguas e à discussão do papel que a tradução exerce, a ponto de Derrida questionar:

'Doch was ist der Geist?', demande en effet Heidegger. Qu'est-ce que l'esprit? Réponse: 'Der Geist ist das Flammende ...' (p. 59). Plus loin, 'Der Geist ist Flamme’ (p. 62). Comment traduire? L'esprit est ce qui enflamme? Plutôt ce qui s'enflamme, mettant feu, mettant le feu à soi-même? L'esprit est flamme. ... $(1987, \text { p. 132-3) })^{13}$ 
Pode-se notar a resistência à tradução, pois embora haja o acolhimento da língua alemã, em itálico, sua presença causa um estranhamento para o leitor e possibilita que ele também coloque em discussão a tradução para o francês. Outro sinal gráfico discutido por Derrida a partir do Geist heideggeriano são as aspas. Novamente a língua do outro fornecerá aquilo que Derrida necessita para definir o que chama de "signaux de lecture" ("sinais de leitura"):

Je rappelle qu'en allemand 'guillemet' se dit Anführungsstriche ou Anführungszeichen. Anführen, conduire, prendre la tête, mais aussi duper, se payer la tête ou bourrer le crâne de quelqu'un. (1987, p. 106) $)^{14}$

O alemão possibilita o embasamento da argumentação de Derrida em relação ao papel das aspas de Geist no texto de Heiddegger, ao mesmo tempo em que nos alerta para seu papel na escritura derridiana, repleta de "sinais de leitura". Outro procedimento encontrado é a citação de traduções lado a lado, especificando o nome do tradutor, às vezes sem nenhum comentário, às vezes adjetivando as traduções:

Les hommes de Sodome veulent voir ces hôtes afin de les 'pénétrer', dit une traduction (celle de Chouraqui: 'Fais-les sortir vers nous: pénétrons-les!'), pour les 'connaître', dit pudiquement une autre (celle de Dhorme dans la Bibliothèque de la Pléiade: 'Fais-les sortir vers nous pour que nous les connaissions'). (Derrida, 1997, p. 133, destaque nosso $)^{15}$

Embora reconheça a possibilidade de mais de uma tradução e declare que não pretende apresentar juízos de valor, Derrida acaba por fazer alguns comentários a respeito da tradução, mesmo que 
se resumam a um único adjetivo, como nesse caso. Essa citação da tradução bíblica é usada para tratar da questão moral e de uma certa ética da hospitalidade, ao mesmo tempo em que enfoca o poder do pai e a questão da hierarquia e da diferença sexual (entregar as filhas no lugar dos homens). Nesse sentido, a tradução de Chouraqui é mais relevante, já que possibilita as referências à questão homossexual de Sodoma.

Mesmo quando Derrida se abstém de fazer qualquer tipo de julgamento, não podemos deixar de lado a necessidade de escolha, especialmente quando apresenta uma tradução incorporada ao texto enquanto outra aparece em nota, ou seja, ele não deixa de eleger uma ou outra para "compor" seu texto. Entretanto, isso não significa que esteja priorizando uma tradução, pois, como ele mesmo afirma, o que muitas vezes parece "secundário, lateral, marginal" importa mais do que os pontos considerados "centrais" (cf. 1991, p. 65).

Embora o objetivo aparentemente não seja fazer um trabalho de tradução comentada, o ato derridiano acaba por instigar o leitor a cotejá-las, conscientizando-o das inevitáveis diferenças entre uma tradução e outra, mostrando a impossibilidade de a língua ser única e a possibilidade de dizer a mesma coisa (que também é outra) de diferentes maneiras na mesma língua.

Uma nota em De l'esprit pode ajudar a comprovar essa hipótese: são elencadas duas traduções utilizadas pelo mesmo tradutor para "Die Sprache west als dieser Zuspruch" (1. La parole se déploie en tant que cette parole adressée. 2. La parole se déploie en tant que cette adresse) (1987, p. 153) ("1. A fala se desenrola como fala dirigida. 2. A fala se desenrola como endereço") (1990a, p. 119). A conclusão de Derrida a respeito das opções do tradutor reitera as diferenças entre as línguas e na própria língua: "Les deux traductions sont justes même si elles sont vouées à être incomplètes et à tenter, en vain, de se compléter" (1987, p. 154) (“As duas traduções estão corretas, mesmo que estejam votadas a ser incompletas e a tentar, em vão, se completar") (1990a, p. 119). 
Assim como uma tradução pode "completar" a outra, o texto original tem a tradução como seu suplemento, como secundária e essencial ao mesmo tempo. Ao mesmo tempo em que afirma que a tradução só pode ser outro texto, transformado, Derrida defende a fidelidade à assinatura e à singularidade do texto de partida. Por conseguinte, invalida as críticas geralmente atribuídas à sua definição de tradução como transformação, pois mostra que, embora essa transformação seja inevitável, ela deve responder ao imperativo do texto, à lei de sua constituição. Derrida mostra ainda que qualquer texto é caracterizado por uma certa intraduzibilidade. Por outro lado, qualquer texto também pode ser visto como um convite à tradução e se constituirá em outro texto, vindo em substituição, transformando o texto de partida. Essa substituição acontece dentro de um jogo de enxertos e suplementos constitutivos e sempre poderá gerar novas substituições, desencadeando novas interpretações e provocando novos efeitos. 


\section{Notas}

1. Santos (2010) retoma essa questão e levanta várias possibilidades de se examinar “o que é desconstrução?”.

2. Para nossas análises, importa o jogo que Derrida faz com o francês e as outras línguas, razão pela qual optamos por citar Derrida em francês. Geralmente assumimos, em nota, as traduções já publicadas em português, explicitando os casos em que a tradução é nossa.

3. “Mas essa tradução de F.-V. Hugo ('tempère'), que não é má, eu estou tentado a substituí-la por outra. Não será uma verdadeira tradução, sobretudo não será uma tradução relevante. Ela não responderá pelo nome de 'tradução'. Ela não devolverá, não saldará, não restituirá tudo, não pagará toda sua dívida, primeiramente a um suposto conceito, a uma identidade de sentido alegada pela palavra 'tradução'. Ela não vai substituir aquilo que chamamos comumente uma tradução, uma tradução relevante" (2000, p. 37).

4. "Uma tradução relevante seria, portanto, simplesmente, uma 'boa' tradução, uma tradução que faz tudo o que dela se espera, uma versão, em suma, que cumpre sua missão, honra sua dívida e faz seu trabalho, ou seu dever, inscrevendo na língua de chegada o equivalente mais 'relevant' de um original, a linguagem a mais precisa, apropriada, pertinente, adequada, oportuna, penetrante, unívoca, idiomática, etc." (2000, p. 17).

5. "Apesar de tudo, parece-me, a tradução deve se esforçar para ser o mais fiel possível, não por cuidado da exatidão calculável, mas porque ela nos chama à lei do outro texto, à sua injunção, à sua assinatura, a esse outro acontecimento na medida em que ele já teve lugar antes de nós, e ao qual devemos responder como herdeiros. Ele está lá, e a traduzir, antes de nós, diante de nós: heterônimo que faz com que eu aceite a lei do outro, não lhe obedecendo passivamente, mas contra-assinando-a, inventando uma assinatura que, na minha língua, numa situação totalmente diferente, numa língua incomensurável, se alie muito estranhamente ao outro e subscreva a lei do outro." (nossa tradução)

6. “Assim quando um 'original' fala de sua língua falando sua língua ele provoca uma espécie de suicídio para a/com a tradução, como se diz suicídio com gás ou 
suicídio com fogo. Melhor suicídio com fogo, porque se deixa destruir quase sem resto, sem resto aparente no interior do corpus.” (nossa tradução)

7. "Teria podido simular o que se chama, em francês, um faux départ (insisto com o tradutor que mantenha as aspas, os parênteses, os itálicos, e o francês) ..." (1991, p. 43).

8. "Não sei como Sam Weber traduzirá 'contre-pied'. Esclareço, pensando nele, que entendo isso primeiro, desde minha adolescência, no código do futebol: ardil ativo para surpreender o adversário engajado numa outra direção" (1991, p. 103).

9. A este respeito, ver nosso artigo (2008) e nossa tese de doutorado (2003).

10. "Embora tenha se imposto alhures com frequência, a palavra francesa intraitable (intratável) é provavelmente difícil de traduzir. Equivale a dizer que a própria palavra intraitable é intratável (por exemplo intraduzível) - e é por isso que eu disse que ela se tinha imposto" (1995, p. 59).

11. "Ter-se-á notado que utilizamos uma tradução consagrada de Platão, a das edições Guillaume Budé, cuja autoridade é reconhecida. Aqui, para o Fedro, aquela de Léon Robin. Continuaremos a fazê-lo, inserindo contudo, quando isto nos parecer oportuno e pertinente quanto a nosso propósito, o texto grego entre parênteses" (1991, p. 15-6).

12. "Talvez, em todo o caso, sejamos mais corretamente sensíveis à sua germanidade se o deixarmos ressoar em uma língua estrangeira, para pô-lo à prova na tradução, ou antes, se pusermos à prova sua resistência à tradução, e se submetermos nossa língua à mesma prova” (1990a, p. 11-2).

13. 'Doch was ist der Geist?', pergunta com efeito Heidegger. Que é o espírito? Resposta: 'Der Geist ist das Flammende ...' (p. 59). Mais longe, 'Der Geist ist Flamme' (p. 62). Como traduzir? O espírito é o que inflama? Antes, o que se inflama, pondo fogo, pondo fogo em si mesmo? O espírito é chama. ... (1990a, p. 102). 
14. "Lembro que em alemão "aspas" se diz Anführungsstriche ou Anführungszeichen. Anführen, conduzir, tomar a frente, mas também enganar, pagar com a cabeça ou enganar alguém" (1990a, p. 83).

15. "Os homens de Sodoma querem ver os hóspedes (hôtes) a fim de 'penetrá-los', diz uma tradução (a de Chouraqui: 'Faça-os sair até nós: penetremo-los!'), para 'conhecê-los', diz pudicamente uma outra (a de Dhorme na Bibliothèque de la Pléiade: 'Faça-os sair até nós para que os conheçamos.')." (nossa tradução)

\section{Bibliografia}

CHAMBERLAIN, L. Gênero e a metafórica da tradução. Tradução de Norma Viscardi. In: OTTONI, P. (Org.). Tradução: a prática da diferença. Campinas: Unicamp, Fapesp, Faep, 1998. p. 33-54.

DERRIDA, J. Introduction. In: HUSSERL, E. L'origine de la géométrie. Paris: Presses Universitaires de France, 1962. p. 3-171.

. Posições. Semiologia e Materialismo. Tradução de Maria M. C. Barahona. Lisboa: Plátamo, 1975.

. De l'esprit. Heidegger et la question. Paris: Galilée, 1987.

. Do espírito. Tradução de Constança Marcondes César. Campinas: Papirus, 1990a.

. Du droit à la philosophie. Paris: Galilée, 1990b.

. Limited Inc. Paris: Galilée, 1990c. 

rus, 1991.

. Limited Inc. Tradução de Constança Marcondes César. Campinas: Papi. Che cos'è la poesia? In: . Points de suspension. Paris: Galilée, 1992a. p. 303-308.

. La pharmacie de Platon. In: Phèdre suivi de La pharmacie de Platon. Paris: Flammarion, 1992b. p. 251-403.

. Passions. Paris: Galilée, 1993.

. Paixões. Tradução de Lóris Z. Machado. Campinas: Papirus, 1995.

. De l'hospitalité. Anne Dufourmantelle invite Jacques Derrida à répondre. Paris: Calmann Lévy, 1997.

. Fidélité à plus d'un. Mériter d'hériter où la généalogie fait défaut. Rencontre de Rabat avec Jacques Derrida. Idiomes, nationalités, déconstructions. Belvédère, Casablanca: Editions Toubkal, 1998, p. 221-265.

. Qu'est-ce qu'une traduction 'relevante'? In: Quinzièmes assises de la tra-

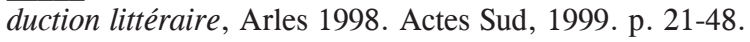

. O que é uma tradução relevante? Tradução de Olívia Niemeyer Santos. $\overline{A l f a . ~ R e v i s t a ~ d e ~ L i n g u i ́ s t i c a . ~ S a ̃ o ~ P a u l o: ~ U N E S P, ~ v .44, ~ 2000, ~ p .13-44 . ~}$

JOHNSON, B. A fidelidade considerada filosoficamente. Tradução de Lenita Esteves. In: OTTONI, P. (Org.). Tradução: a prática da diferença. Campinas: Unicamp, Fapesp, Faep, 1998. p. 27-32.

MENDES, A.G. Obituary: Jacques Derrida. The Economist, 21 out. 2004. Disponível em http://www.economist.com/node/3308320, acesso em 24/01/2011.

SANTOS, Olivia N. Os Estudos de Tradução e Jacques Derrida: Afinal, O que é Desconstrução? In: Tradução \& Comunicação, n. 20, São Paulo: Unibero, 2010, 
p. 105-112. Disponível em: http://sare.unianhanguera.edu.br/index.php/rtcom/ article/viewFile/1966/879, acesso em 24/01/2011.

SISCAR, M. Jacques Derrida, o intraduzível. Alfa. Revista de Linguística. São Paulo: UNESP, v. 44, 2000, p. 59-70. 